\title{
A 15-year-old boy with huge facial swelling, recurrent severe epistaxis, progressive proptosis, nasal obstruction and impaired hearing on right side
}

\author{
Md. Asaduzzaman, Shamsul Alam, Md. Wares Uddin, K. M. Tarikul Islam, Mahmudul Hasan
}

\section{Article Info \\ Department of Oral and Maxillofacial Surgery, Faculty of Dentistry, Banga- bandhu Sheikh Mujib Medical Universi- ty, Shahbag, Dhaka, Bangladesh (MA MWU, MH); Department of Neurosur- gery, Faculty of Surgery, Bangabandhu Sheikh Mujib Medical University, Shahbag, Dhaka, Bangladesh (SA, KMTI) For Correspondence: Md. Asaduzzaman \\ asaduzzamanuzzal.bsmmu@gmail.com \\ Received \\ Accepted: \\ 12 November 2019 \\ Available Online: 24 December 2019 \\ ISSN: 2224-7750 (Online) \\ 2074-2908 (Print) \\ DOI: 10.3329/bsmmuj.v12i4.43985}

Keywords: Angiofibroma; Epistaxis Facial swelling; Impaired hearing; Nasa obstruction; Nasopharyngeal; Proptosis

\section{Cite this article:}

Asaduzzaman M, Alam S, Uddin MW, Islam KMT, Hasan M. A 15-year-old boy with huge facial swelling, recurrent severe epistaxis, progressive proptosis, nasal obstruction and impaired hearing on right side. Bangabandhu Sheikh Mujib Med Univ J. 2019; 12: 199-203.

\section{Copyright:}

The copyright of this article is retained by the author(s) [Atribution CC-By 4.0]

Available at:

www.banglajol.info

A Journal of Bangabandhu Sheikh Mujib Medical University, Dhaka, Bangladesh

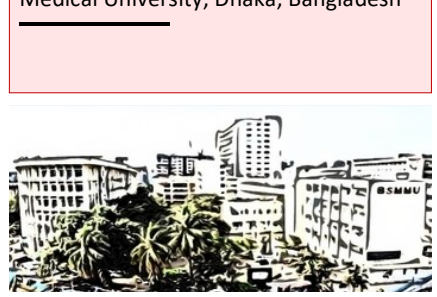

\section{Presentation of Case}

Dr. Mahmudul Hasan (MS Resident): A 15-yearold male hailing from Khagrachhari was admitted into the department with the complaints of swelling on the right side of face for 10 months with recurrent severe epistaxis, progressive proptosis, unilateral nasal obstruction and impairment of hearing for two months (Figure 1). On extraoral examination, there was a firm non-tender, nonmobile, fixed swelling on the right side of cheek causing facial asymmetry measuring about $10 \times 12 \mathrm{~cm}$ in size extending from upper eyelid to middle of the right cheek supero-inferiorly and pre-auricular area to the medial wall of nose posteroanteriorly. There was deviation of nose towards the opposite left side with obstruction of right nostril by the mass and anosmia. There was ectropion of right eye due to the pushing effect of the mass. Impaired hearing on the right ear for two months. On intraoral examination, there was a firm non-tender, non-mobile, fixed swelling on the right side of oral cavity occupying hard palate, soft palate, oropharynx measuring about $6 \times 5 \mathrm{~cm}$ causing difficulties in mastication. The patient was ill-looking, anemic, having no signs of dehydration, jaundice, no significant lymphadenopathy, normal vital signs, and no organomegaly. Systemic examinations revealed no abnormality for this patient.

Dr. Md. Asaduzzaman (Assistant Professor): The results of red blood cell showed anisopoikilocytosis with many microcytic hypochromic red cells, some target cells and rouleaux formation. The results of white blood cells indicated that it was mature with normal in count and increased neutrophils distribution (Table I). There was an increase of platelet count with a few giant platelets.

There was enhanced soft tissue mass in the right maxillary sinus with extensive contiguous extension in the right nasal fossa, posterior choana, cheek, sphenoid sinus, intracranial extradural extension through floor of middle cranial fossa behind the apex of orbit.

Histological sections showed the proliferation of fibroblastic cells, interspersed with vascular channel. The case was diagnosed as angiofibroma.

\section{Provisional Diagnosis}

Juvenile nasopharyngeal angiofibroma

\section{Differential Diagnosis}

Dr. Asaduzzaman: The boy with a history of recurrent severe epistaxis with progressive nasal obstruction, proptosis and impaired hearing usually may be a case of juvenile nasopharyngeal angiofibroma. Juvenile nasopharyngeal angiofibroma is a slowly growing benign tumor, which is highly vascular, locally aggressive and vasoformative neoplasm presents mostly common in adolescent male whose median age is 14 years. 1 It is the most common benign neoplasm of the nasopharynx, 2 In the head and neck region, juvenile nasopharyngeal angiofibroma is a relatively rare, represent approximately $0.5 \% . \underline{3} 75 \%$ of all patients presented with the epistaxis and nasal obstruction. The symptoms may persist for months to years. Most of the cases, the tumor shows no symptom until it is increased and encroach on critical structure. 4 The entire feature matched with this case but it needs histopathological examination for confirmatory diagnosis. As the tumor is a vascular one and has a high risk of huge bleeding during biopsy, it is better to use radiographic imaging for the differential diag-

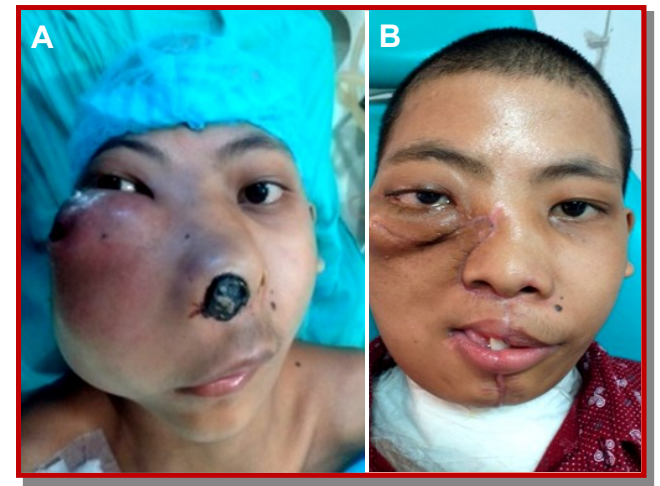

Figure 1: Patient before (A) and after (B) operation 


\begin{tabular}{|c|c|c|}
\hline \multicolumn{3}{|l|}{ Table I } \\
\hline \multicolumn{3}{|l|}{ Laboratory findings } \\
\hline Investigation & Result & Reference \\
\hline Hemoglobin $(\mathrm{g} / \mathrm{dL})$ & 5.5 & $15 \pm 2$ \\
\hline Erythrocyte sedimentation rate (mm in 1st hour) & 106 & $0-11$ \\
\hline White blood cell $\left(\times 10^{9} / \mathrm{L}\right)$ & 10 & $7.0 \pm 3.0$ \\
\hline Neutrophil (\%) & 78 & $40-80$ \\
\hline Lymphocyte (\%) & 16 & $20-40$ \\
\hline Monocyte (\%) & 3 & $2-10$ \\
\hline Eosinophil (\%) & 3 & $1-6$ \\
\hline Red blood cell $\left(\times 10^{12} / \mathrm{L}\right)$ & 3.6 & $5 \pm 0.5$ \\
\hline Platelet $\left(\times 10^{9} / \mathrm{L}\right)$ & 550 & $150-450$ \\
\hline Packed cell volume (\%) & 17.8 & $45 \pm 5$ \\
\hline Mean corpuscular volume (fL) & 48.5 & $92 \pm 9$ \\
\hline Mean corpuscular hemoglobin (pg) & 13.6 & $29.5 \pm 2.5$ \\
\hline Mean corpuscular hemoglobin concentration $(\mathrm{g} / \mathrm{dL})$ & 28.1 & $33 \pm 1.5$ \\
\hline
\end{tabular}

nosis before definitive diagnosis.

For this reason, CT scan and MRI are the best option of imaging. All causes of a nasopharyngeal mass, epistaxis, and orbital swelling should be included in the differential diagnosis.

\section{Sinonasal angiomatous polyp}

Dr. Ruman Banik (Medical Officer): Sinonasal angiomatous polyp is a non-tumorous lesion of the nose and paranasal sinus. $\frac{5}{}$ Its clinical and radiological features nearly match with the nasopharyngeal angiofibroma. For this reason, a radiologist often confuse in diagnosis of sinonasal angiomatous polyp with other benign and malignant tumors.

\section{Rhabdomyosarcoma}

Dr. Banik: Rhabdomyosarcoma is a highly malignant tumor of the striated muscle. 6 This type of tumor is common in pediatric patient but it is uncommon in nose and paranasal sinus. But when it arises from this area it may raise similar clinical and radiological feature of nasopharyngeal angiofibroma.

\section{Nasopharyngeal carcinoma}

Dr. Banik: Nasopharyngeal carcinoma is a common tumor of the nose and paranasal sinus in the late age. 7 Clinical presentation is usually late but when it appears, already there is distant metastasis. The late clinical presentation is usually epistaxis, conductive hearing loss, nasal obstruction, fullness of cheek, which is similar to the presentation of nasopharyngeal angiofibroma.

\section{Nasopharyngeal teratoma}

Dr. Banik: Nasopharyngeal teratoma is a congenital tumor of two or three germ layer of childhood. 8 But may occur at any age. The clinical presentations are usually nasal blockage, difficulty in breathing, rhinorrhea, snoring, respiratory distress, dysphasia, etc. If it grows bigger that it may mimic radiologically nasopharyngeal angiofibroma.

\section{Nasopharyngeal lymphoma}

Dr. Banik: Nasopharyngeal lymphoma usually occurs in the middle or late age group. 2 But it may occur in any age group. When it occurs in the nasopharyngeal area, it may cause nasal obstruction, nasal stiffness, headache or fever of unknown origin.

\section{Lymphangioma}

Lymphangioma is a childhood tumor of lymphatic system but is rare in nasopharyngeal location. Presenting complaints may be nasal obstruction, swelling of the nose and cheek area. Radiologically it may mimic the nasopharyngeal angiofibroma. $\underline{10}$

\section{Encephalocele}

When extracranial herniation of the intracranial content occurs that maintain a connection with subarachnoid space, then encephalocele develop. $\underline{11}$ It also may mimic radiologically with the nasopharyngeal angiofibroma.

\section{Esthesioneuroblastoma}

Dr. Banik: This tumor is benign in nature and arising from the basal layer of the olfactory epithelium which grows slowly and tends to destroy the surrounding bone.12 It also may mimic radiologically with the nasopharyngeal angiofibroma.

\section{Dr. Asaduzzaman's Diagnosis}

Juvenile nasopharyngeal angiofibroma stage IIIB

\section{Discussion}

\section{Regarding diagnosis of the case}

Dr. Md. Wares Uddin (Associate Professor): In this case, the patient received some investigation for the evaluation of general condition and specific investigation was performed for the tumor itself. Complete blood count was advised to find out the hypochromic microcytic anemia due to chronic blood loss. Furthermore, plain lateral skull radiograph and combined $\mathrm{CT}$ scan and MRI were performed to determine the exact extent or stage of the tumor, $\underline{13}$ diagnostic angiography for evaluating the source of blood supply. Transnasal biopsy for confirmatory diagnosis was also done. $\underline{\underline{14}}$ 


\section{Regarding treatment plan}

Dr. Asaduzzaman: It was suggested that surgery is the primary treatment at the early stage of tumor and complete surgical excision can provide a cure of patient without causing excessive morbidity..$\underline{15}$ However, controversy in the treatment approach can vary when the patient presents with more advanced disease. In the case of cranial base extension or intracranial involvement, it is difficult for the maxillofacial surgeon or neurosurgeon to completely excise the tumor alone. For this reason, it needs multidisciplinary approach. Endoscopic transnasal approach has advantages over the noncosmetic sequelae that it is associated with minimum hemorrhage or deformity of the facial skeleton. In the juvenile nasopharyngeal angiofibroma surgery, the endoscopic approach is effective in the visualization of tumor and there is minimum hemorrhage, enables to dissection and ligature of the vessel too. 16 Furthermore, simultaneous endoscopic surgery or a combination of endoscopic and open surgical approaches may be helpful for better visualization of the lesion and facilitates total removal. 16,17 However, currently external surgical approach is said favorable for the removal of more advanced tumor, $\underline{\underline{18}}$ and it is also recommended for the juvenile nasopharyngeal angiofibroma.

\section{Regarding technique of bleeding control}

Dr. K. M. Tarikul Islam (Associate Professor, Neurosurgery): Several techniques such as rapid sequence of induction, hypotensive anesthetic techniques and hypothermia have been recommended for bleeding control.19 Furthermore, it is also important to place the patient in reverse Trendelenburg position for the reduction of blood flow to the tumor side and deliberate hypotension anesthesia. As there is always a risk of massive blood loss, two or more venous accesses for blood replacement should be in place such as two/three large bore intravenous catheters. Moreover, angiography of the patient should be performed to identify the vascularity of juvenile nasopharyngeal angiofibroma because it plays a major role in preoperative embolization. It should be done as early as 24 hours preoperatively because juvenile nasopharyngeal angiofibroma is known to achieve rapid revascularization. $\underline{20}$ However, as the embolization creates the risk of incomplete excision, it is necessary to reduce the definition of tumor border, especially when there is deep invasion of the complex sphenoid bone.21 Andrade et al. (2007) 22 did not use embolization even in advanced stages III and IV tumors due to difficulties of complete tumor resection. Therefore, it may be better that we can do carotid ligation rather than embolization. Moreover, embolization may cause serious intracranial complications.

Regarding surgical approach for extracranial part of juvenile nasopharyngeal angiofibroma

Dr. Asaduzzaman: It is primarily determined by tumor location, extension, structure involved and surgical expertise. The approaches are inferior, lateral and anterior types. Inferior approaches are transpalatal and transoral-transpharyngeal approach whereas anterior approaches include transnasal, Le Fort I maxillotomy, medial maxillectomy and maxillary swing and the lateral approach is infratemporal fossa approach. The modified transpalatal approach is the removal of pterygoid plates. Transnasal approach may be useful for the tumor within the nasopharynx, nasal cavity and sphenoid sinus. The lateral exposure is very limited with this technique. However, the Le Fort I maxillary osteotomy approach creates access to tumor within the nasopharynx, nasal cavity, paranasal sinuses, pterygopalatine fossa, and tumor with minimum extension into the infratemporal fossa. $\underline{23,24}$ Furthermore, Le Fort I osteotomy is also suitable for the tumor localized in the nasal cavity and nasopharynx, $\underline{23}$ but the excision of pterygoid plate with modified transpalatal approach may access the pterygopalatine fossa. On the other hand, the medial maxillotomy approach can be employed to access tumor in the nasopharynx, orbit, pterygopalatine fossa, infratemporal fossa, ethmoidal and sphenoid sinus and the cavernous sinus medial part. Moreover, it may performed through a lateral rhinotomy or WeberFerguson approach or by midfacial degloving or modified midfacial degloving incision. 24 In this case, as the extension of tumor was to ethmoidal sinus, nasopharynx, nasal cavity, right masticator space, right ITF, sphenoidal sinus, middle cranial fossa, the use Weber-Ferguson approach with removal of part of resorbed maxilla was performed.

\section{Regarding operative procedure}

Dr. Asaduzzaman: In the preoperative preparation, $\mathrm{CV}$ line was done through right subclavian vein. Tracheostomy was done. Eight units of whole blood were arranged for par operative needs.

Regarding surgical procedure for extracranial part of juvenile nasopharyngeal angiofibroma

First surgery was done on 10 April 2019. After all aseptic preparation, proper draping and under general anesthesia, the external carotid artery was ligated through submandibular incision which was extended up to lip split. Weber Ferguson incision was given and the flap was retracted. Medial maxillectomy was done. The tumor mass was exposed and identified. Internal maxillary artery and the ascending pharyngeal artery was ligated by gently retracted the tumor and surrounding bleeding was controlled by pressure pack. Tumor was removed from the infratemporal space, buccal space, nasal cavity, ethmoidal sinus, maxillary sinus, masticator space, nasopharynx, oropharynx and hard palate. Intracranial, sphenoidal and lateral pharyngeal part of the tumor was not touched because of huge bleeding from the tumor mass. With great care, hemostasis was achieved and the surgical obturator 


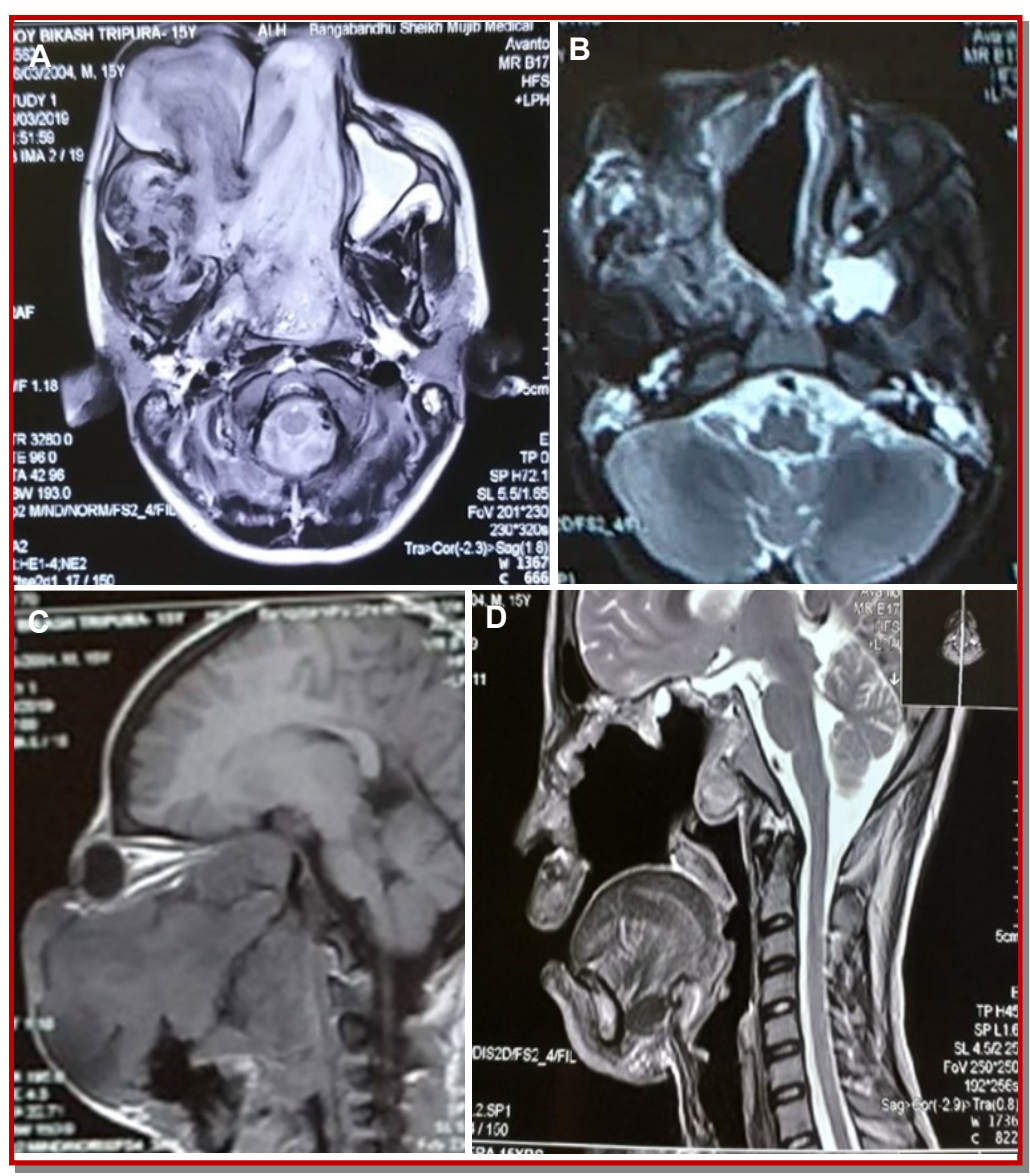

Figure 2: Preoperative MRI axial view (A); Postoperative MRI axial view (B); Preoperative sagittal view of MRI (C); Postoperative MRI sagittal view (D)

was fixed. Wounds were closed in layers and the gap was filled with antibiotic soaked gauge pack. Peroperative fluid loss was about 6 liters and the fluid given about 8 liters, transfused 6 unit of whole blood. The tumor mass along with maxilla was sent for histopathology.

Neurosurgical procedure for intracranial part of juvenile nasopharyngeal angiofibroma

Dr. Shamsul Alam (Assistant Professor, Neurosurgery): Second surgery was started on 25 May, 2019. After all aseptic preparation and proper draping, under general anesthesia, we did orbitozygomatic craniotomy and Hakuba's technique, temporal dural peeling and exposure of juvenile nasopharyngeal angiofibroma of the middle cranial fossa by a curvilinear scalp incision keeping head placed on horse-shoe head rest. There were bony irregularities on middle cranial fossa with enlargement of foramen rotundum and superior orbital fissure. Bony irregularities were removed by drilling. Following dural separation capsulated juvenile nasopharyngeal angiofibroma was devascularized by circumferential dissection and hemostasis was done by bipolar cautery. While dissection from cavernous sinus, there was bleeding which was controlled by gel foam and cotton pack. Total exposure was extradural. Following removal of juvenile nasopharyngeal angiofibroma, cavernous sinus contents were preserved including cavernous branch of carotid artery. Hemostasis was ensured. The wound was closed in multilayer keeping a subgaleal drain.

Dr. Asaduzzaman: After removal of intracranial part of tumor, in the same setting through previous scar mark of Weber Ferguson incision, parapharyngeal and sphenoidal part of the tumor was removed. Then, retracting the flap pterygoid plate was identified and removed for better visualization, we identified the tumor and removed it through blunt dissection. Surgical obturator was fixed and the wound was closed in layers and the gap was filled with antibiotic soaked gauge pack. Patient's recovery was uneventful.

\section{Follow-up}

Dr. Asaduzzaman: Post-operative histopathological sections showed angiofibroma composed of proliferation blood vessel with thin walled, irregular fibrous stroma and the tumor was ulcerated involving the bone. Post-operative MRI follow-up shows evidence of free of tumors (Figure 2). Post operative follow-up photograph shows reduced swelling and proptosis (Figure 2), and also improvement of hearing, nasal obstruction and mastication. Nasopharyngeal angiofibroma can be easily excised with endoscopic approach when it is small (stage I, II, IIIA) but it is very difficult when it is large (stage IIIB, IV), it needs multidisciplinary surgical approach. Although there are many methods of managing the patient with juvenile nasopharyngeal angiofibroma, open surgery still remains the preferred treatment for this vascular tumor. 4

\section{Final Diagnosis}

Juvenile asopharyngeal angiofibroma stage IIIB

\section{References}

1. Wiatrak BJ, Koopmann CF, Turrisi AT. Radiation therapy as an alternative to surgery in the management of intracranial juvenile nasopharyngeal angiofibroma. Int J Pediatr Otorhinolaryngol. 1993; 28: 51-61.

2. Sivanandan R, Fee WW. Benign and malignant tumors of the nasopharynx. In: Cummings Otolaryngology: Head and neck surgery. Cummings CW, Haughey BH, Harker LA (eds). Philadelphia, Mosby, 2004, pp 1669-84.

3. Jacobsson M, Petruson B, Svendsen P, Berthelsen B. Juvenile nasopharyngeal angiofibroma: A report of eight cases. Acta Otolaryngol. 1988; 105: 132-39. 
4. Hodges JM, McDevitt AS, El-Sayed Ali AI, Sebelik ME. Juvenile nasopharyngeal angiofibroma: Current treatment modalities and future considerations. Indian J Otolaryngol Head Neck Surg. 2010; 62: 236-47.

5. Schmaier AH. PolyP's many faces. Blood 2016; 128: 1669-70.

6. Dasgupta R, Fuchs J, Rodeberg D. Rhabdomyosarcoma. Semin Pediatr Surg. 2016; 25: 276-83.

7. Chua MLK, Wee JTS, Hui EP, Chan ATC. Nasopharyngeal carcinoma. Lancet 2016; 387: 1012-24.

8. Bayır Ö, Güneri EA, Dilek M, Özer E, Çakmakçı H, Erdağ TK. Nasopharyngeal mature teratoma in the newborn. Türk Pediatri Arşivi. 2014; 49: 257-60.

9. Kmieciak L, Hague DW, Neumann ZL, Joslyn S. What is your neurologic diagnosis? Nasopharyngeal lymphoma. J Am Vet Med Assoc. 2016; 248: 613-16.

10. Legras A, Mordant P, Le Pimpec-Barthes F, Riquet M. Lymphangioma and lymphangiectasia. Rev Pneumol Clin. 2013; 69: 272-77.

11. Gandhoke GS, Goldschmidt E, Kellogg R, Greene S. Encephalocele development from a congenital meningocele: Case report. J Neurosurg Pediatr. 2017; 20: 419-22.

12. Roxbury CR, Ishii M, Gallia GL, Reh DD. Endoscopic management of esthesioneuroblastoma. Otolaryngol Clin North Am. 2016; 49: 153-65.

13. Jian JJ, Cheng SH, Prosnitz LR, Tsai SY, Tsai MJ, Huang AT. T classification and clivus margin as risk factors for determining locoregional control by radiotherapy of nasopharyngeal carcinoma. Cancer 1998; 82: 261-67.

14. Zalvan $\mathrm{CH}$, Brown DJ, Oiseth SJ, Roark RM. Comparison of transnasal laryngoscopic office based biopsy of laryngopharyngeal lesions with traditional operative biopsy. Eur Arch Otorhinolaryngol. 2013; 270: 2509-13.

15. Tewfik TL, Tan AK, Noury A. Juvenile nasopha- ryngeal angiofibroma. J Otolaryngol. 1999; 28: 14551

16. Roger G, Huy PTB, Froehlich P, Van Den Abbeele T, Klossek JM, Serrano E, Garabedian EN, Herman P. Exclusively endoscopic removal of juvenile nasopharyngeal angiofibroma: Trends and limits. Arch Otolaryngol Head Neck Surg. 2002; 128: 92835.

17. Nicolai P, Berlucchi M, Tomenzoli D, Cappiello J, Trimarchi M, Maroldi R, Battaglia G, Antonelli AR. Endoscopic surgery for juvenile angiofibroma: When and how. Laryngoscope 2003; 113: 775-82.

18. Shires CB, Boughter JD, Sebelik ME. Sphenopalatine artery ligation: A cadaver anatomic study. Otolaryngol Head Neck Surg. 2011; 145: 494-97.

19. Ezri T, Roth Y, Geva D, Konichezky S, Marshak G, Halperin D. Aesthetic management of juvenile nasopharyngeal angiofibroma resection. J Cardiothor Vasc An. 2003; 17: 622-24.

20. Carrau RL, Snyderman CH, Kassam AB. Juvenile angiofibroma. In: Operative otolaryngology: Head and neck surgery. Myers EN (ed). Philadelphia, WB Saunders, 2008, pp 39-49.

21. Lloyd G, Howard D, Phelps P, Cheesman A. Juvenile angiofibroma: The lessons of 20 years of modern imaging. J Laryngol Otol. 1999; 113: 127-34.

22. Andrade NA, Pinto JA, Nóbrega Mde O, Aguiar JE, Aguiar TF, Vinhaes ES. Exclusively endoscopic surgery for juvenile nasopharyngeal angiofibroma. Otolaryngol Head Neck Surg. 2007; 137: 492-96.

23. Albuquerque MA, Carvalho Ddo C, Grandez D, Bonilla LF, Cavalcanti MG. Nasopharyngeal angiofibroma. Surgical approach using a transoral Le Fort I osteotomy following embolization: A case report. Oral Surg Oral Med Oral Pathol Oral Radiol Endod. 2009; 107: 180-84.

24. Cansiz H, Güvenç MG, Sekercioğlu N. Surgical approaches to juvenile nasopharyngeal angiofibroma. J Craniomaxillofac Surg. 2006; 34: 3-8. 